Erratum

\title{
Erratum: Yuan, J. et al. Review of the D2D Trusted Cooperative Mechanism in Mobile Edge Computing. Information 2019, 10, 259
}

\author{
Jie Yuan ${ }^{1} * * \mathbb{C}$, Erxia $\mathrm{Li}^{2}$, Chaoqun Kang ${ }^{2}$, Fangyuan Chang ${ }^{2}$ and Xiaoyong $\mathrm{Li}^{1}$ \\ 1 Key Laboratory of Trustworthy Distributed Computing and Service (Beijing University of Posts and \\ Telecommunications), Ministry of Education, Haidian District, Beijing 100876, China; lxyxjtu@163.com \\ 2 China Electric Power Research Institute, Haidian District, Beijing 100192, China; \\ lierxia@epri.sgcc.com.cn (E.L.); kangchaoqun@epri.sgcc.com.cn (C.K.); \\ changfangyuan@epri.sgcc.com.cn (F.C.) \\ * Correspondence: yuanjie@bupt.edu.cn
}

Received: 11 October 2019; Accepted: 14 October 2019; Published: 16 October 2019

The authors wish to make the following corrections to this paper [1].

In "Funding":

This work was supported in part by the project "Research on Security Architecture for Next Generation Distribution Automation System of State Grid Corporation of China".

should be replaced with

This work was supported by the project "Research on Key Technologies of Trusted Analysis and of Business Security in Distribution Automation System (PDB 17201800158)" of the State Grid Corporation of China.

The authors would like to apologize for any inconvenience caused to the readers by these changes. The change does not affect the scientific results.

Conflicts of Interest: The authors declare no conflict of interest.

\section{Reference}

1. Yuan, J.; Li, E.; Kang, C.; Chang, F.; Li, X. Review of the D2D Trusted Cooperative Mechanism in Mobile Edge Computing. Information 2019, 10, 259. [CrossRef]

(C) 2019 by the authors. Licensee MDPI, Basel, Switzerland. This article is an open access article distributed under the terms and conditions of the Creative Commons Attribution (CC BY) license (http:/ / creativecommons.org/licenses/by/4.0/). 